\title{
Collaborative care for patients with depression and diabetes mellitus: a systematic review and meta-analysis
}

\author{
Yafang Huang ${ }^{1}$, Xiaoming $\mathrm{Wei}^{2}$, Tao $\mathrm{Wu}^{3}$, Rui Chen ${ }^{1}$ and Aimin Guo ${ }^{1 *}$
}

\begin{abstract}
Background: Diabetic patients with depression are often inadequately treated within primary care. These comorbid conditions are associated with poor outcomes. The aim of this systematic review was to examine whether collaborative care can improve depression and diabetes outcomes in patients with both depression and diabetes.

Methods: Medline, Embase, Cochrane library and PsyINFO were systematically searched to identify relevant publications. All randomized controlled trials of collaborative care for diabetic patients with depression of all ages who were reported by depression treatment response, depression remission, hemoglobin A1c (HbA1c) values, adherence to antidepressant medication and/or oral hypoglycemic agent were included. Two authors independently screened search results and extracted data from eligible studies. Dichotomous and continuous measures of outcomes were combined using risk ratios (RRs) and mean differences (MDs) with 95\% confidence intervals (Cls) either by fixed or random-effects models.
\end{abstract}

Results: Eight studies containing 2,238 patients met the inclusion criteria. Collaborative care showed a significant improvement in depression treatment response $(\mathrm{RR}=1.33,95 \% \mathrm{Cl}=1.05-1.68$ ), depression remission (adjusted $\mathrm{RR}=1.53,95 \% \mathrm{Cl}=1.11-2.12)$, higher rates of adherence to antidepressant medication $(\mathrm{RR}=1.79,95 \% \mathrm{Cl}=1.19-2.69)$ and oral hypoglycemic agent $(\mathrm{RR}=2.18,95 \% \mathrm{Cl}=1.61-2.96)$, but indicated a non-significant reduction in $\mathrm{HbA} 1 \mathrm{C}$ values $(\mathrm{MD}=-0.13,95 \% \mathrm{Cl}=-0.46-0.19)$.

Conclusions: Improving depression care in diabetic patients is very necessary and important. Comparing with usual care, collaborative care was associated with significantly better depressive outcomes and adherence in patients with depression and diabetes. These findings emphasize the implications for collaborative care of diabetic patients with depression in the future.

Keywords: Collaborative care, Depression, Diabetes mellitus, Systematic review, Meta-analysis

\section{Background}

Depression and diabetes mellitus (DM) are two of the most prevalent chronic diseases around the world, which frequently co-occur [1-5]. Approximately $20 \%$ of patients with DM meet diagnostic criteria for depression $[4,5]$. Diabetic patients with depression are associated with decreased glycated hemoglobin control, lower adherence to diet, exercise and taking medications, comparing with those without depression [6-9]. Moreover, depression had

\footnotetext{
*Correspondence: guoaiminlaoshi@126.com

${ }^{1}$ School of General Practice and Continuing Education, Capital Medical University, Beijing 100069, China

Full list of author information is available at the end of the article
}

an increased risk in diabetes development and adverse diabetes outcomes, such like microvascular and macrovascular complications [10,11].

Patients with diabetes and depression are usually poorly managed in primary care $[7,12]$. Depression is associated with failures to detect and diagnose in diabetic patients [13]. Diabetes also weaken the effectiveness of depression treatments $[14,15]$. Depression care needs to be improved especially in people with diabetes and vice versa. The most common method of treatments for diabetes and depression in primary care are taking medications of oral hypoglycemic agents and antidepressants. However, diabetes patients with depression are more likely to have problems and concerns

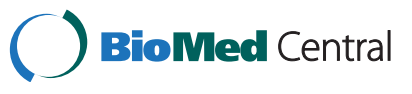


with medication, such like fear of side effects and addiction, than those patients without depression [1,15-17]. Conventional psychological interventions fail to improve both physical and mental health outcomes in diabetes patients with depression [18].

Collaborative care is a new model pointing out coordinated care management in primary practices, which involving primary care physicians, nurses and other specialists or professionals who provided patient-orientated and guideline-based management to patients at the primary care level [12,19-22]. It is originally conducted on depressive patients. More studies of collaborative care have been diversified to those patients with chronic illnesses [19,23]. Nowadays, collaborative care attracts a worldwide interest in its potential effectiveness in achieving certain clinically improvements and public health benefits [12,19-21,24,25]. Several randomized controlled trials (RCTs) indicated that collaborative care significantly improved control of both depression and diabetes [19,26,27]. However, some studies concluded that collaborative care improved depression outcome alone [23,28]. There is no consensus on these results. We still do not know whether collaborative care work as a truly integrated intervention that improve both depression and diabetes outcomes.

We therefore conducted a systematic review and metaanalysis to examine whether a primary care based collaborative care would improve depression and diabetes outcomes in patients with both depression and diabetes.

\section{Methods}

\section{Publication search}

Literature searches were conducted through March 27, 2013 using the electronic databases Medline (1946 to present), Embase (1980 to present), Cocharne library (present) and PsycINFO (1806 to present). The detailed search strategies were shown in Additional file 1 . No restriction was placed on type of language. We also screened the references from retrieved articles and reviews to identify additional articles which met the eligibility criteria.

\section{Study selection}

Studies that met the following criteria were included in this meta-analysis: (1) Participants: both male and female patients of any age, with a diagnosis of both depression and diabetes. Diagnosis of depression was according to one of the following: a, diagnosis made by primary care physicians; b, current prescription for an antidepressant; c, diagnosis according to International Classification of Diseases, Ninth Revision (ICD-9) code, Diagnostic and Statistical Manual (DSM) and/or Research Diagnostic Criteria (RDC); d, assessment through clinician-rated and/ or self-rated validated instruments, for example, patient health questionnaire (PHQ); e, diagnosis made through structured psychiatric interview. Diagnosis of diabetes was according to one of the following: a, diagnosis made by primary care physicians; b current prescription for a glucose lowering medication; $\mathrm{c}$, diagnosis according to ICD-9 code; d, diagnosis according to laboratory result. (2) Type of intervention: although there was considerable variability in the exact nature of the intervention [29], we regarded that if it fulfilled the following four criteria as the intervention of collaborative care: $a$, a multi-professional patient care; $b$, a structured management plan; c, scheduled patient follow up; d, enhanced inter-professional communication [30]. (3) Type of control: we regarded it as control according to one of the following: a. no additional intervention was provided; b. usual care was provided in the control group; c. enhanced usual care was provided in the control group. (4) Type of outcome measurements: the studies were included if one of the following outcomes were reported in the original article: $a$, depression treatment response; $b$, depression remission; c, hemoglobin A1c (HbA1c) control; $\mathrm{d}$, adherence to medication (including adherence of oral hypoglycemic agents and/or antidepressants); (5) Type of studies: only clinical randomized controlled trials (RCTs) or cluster RCTs were eligible; (6) Setting: primary care settings.

Studies that did not meet the above criteria were excluded. In addition, those duplicated publications were excluded. Two authors (YH TW) independently evaluated the articles for inclusion. Any discrepancies were resolved by further discussion and consultation of a third author $(\mathrm{XW})$. The selection process by means of a flow chart was presented in Figure 1.

\section{Data extraction}

A standardized data extraction form was used. The following information was extracted: first author name, publication year, country of corresponding author, study design, study period, age, gender, ethnicity, sample size (intervention/control), length of follow-up, conflicts of interest (Table 1), inclusion criteria of patients, description of "collaborative care" and "control", main outcomes (see Additional file 2). All the corresponding authors of studies included in qualitative synthesis were contacted by e-mail a maximum of 3 times to obtain additional information. However, no information was received from the original authors.

\section{Quality assessment}

The risk of bias for the included studies was assessed using the Cochrane Collaboration's tool for assessing risk of bias [34]. Two authors (XW TW) independently assessed the methodological quality of RCTs using the Cochrane risk of bias tools. Any discrepancies were resolved by a third author (RC). 


\section{Statistical analysis}

Primary clinical outcomes of interest, evaluated at the end of follow up, 6 months and 12 months of follow up (during which patients were on collaborative care intervention) respectively, included depression treatment response (defined as $50 \%$ or more decrease in the Hopkins Symptoms Checklist-20 (SCL-20) score from base line); depression remission (defined as SCL-20 score less than 0.5); diabetes clinical outcomes (HbA1c values) (defined as HbA1c measures exposure of red blood cells to glucose during a 90-day period). Secondary outcomes were adherence (defined as the percentage of prescribed doses taken, calculated as the number of doses taken divided by the number of doses prescribed over the observation period *100\%) to antidepressant medication and oral hypoglycemic agent (which was dichotomized at a threshold of $80 \%$ ) [35].

We used Revman software (version 5.2), which was available through the Cochrane Collaboration (www.cochrane. org). Heterogeneity was quantified with a Chi-square heterogeneity statistic and by means of I square, with a predefined significance threshold of 0.1 [36]. If a significant trend for heterogeneity was observed, a random effect model via generic inverse variance weighting was used to combine the effect [37]. Otherwise, we used a fixed-effects model to calculate the pooled effects. Results were expressed as the relative risks (RRs) with 95\% confidence intervals (CIs) for dichotomous variables and 
Table 1 Characteristic of the included studies

\begin{tabular}{|c|c|c|c|c|c|c|c|c|c|c|c|c|}
\hline Author & Year & Country & $\begin{array}{l}\text { Study } \\
\text { design }\end{array}$ & $\begin{array}{l}\text { Study period } \\
\text { conducted }\end{array}$ & Setting & $\begin{array}{l}\text { Age, } \\
\text { mean }(y)\end{array}$ & $\begin{array}{l}\text { Gender, } \\
\text { male (\%) }\end{array}$ & $\begin{array}{l}\text { Ethnicity, } \\
\text { white (\%) }\end{array}$ & $\begin{array}{l}\text { Randomized } \\
\text { sample size } \\
\text { (Intervention/control) }\end{array}$ & Follow-up & $\begin{array}{l}\text { Loss to follow-up based } \\
\text { on primary outcome (\%) }\end{array}$ & $\begin{array}{l}\text { Intention-to- } \\
\text { treat analysis }\end{array}$ \\
\hline \multirow[t]{2}{*}{ Bogner et al. [26] } & \multirow[t]{2}{*}{2012} & \multirow[t]{2}{*}{ US } & \multirow[t]{2}{*}{$\mathrm{RCT}$} & \multirow[t]{2}{*}{$\begin{array}{l}\text { From April } 2010 \\
\text { to April } 2011\end{array}$} & \multirow[t]{2}{*}{$\begin{array}{l}3 \text { Primary } \\
\text { care practices }\end{array}$} & \multirow[t]{2}{*}{57} & \multirow[t]{2}{*}{$58(32)$} & \multirow[t]{2}{*}{$65(36)$} & \multirow[t]{2}{*}{$92 / 88$} & \multirow[t]{2}{*}{$6,12 w k$} & $\begin{array}{l}\text { Intervention group: } \\
0 / 92(0 \%)\end{array}$ & \multirow[t]{2}{*}{ Used } \\
\hline & & & & & & & & & & & $\begin{array}{l}\text { Control group: } \\
0 / 88(0 \%)\end{array}$ & \\
\hline \multirow[t]{2}{*}{ Bogner et al. [27] } & \multirow[t]{2}{*}{2010} & \multirow[t]{2}{*}{ US } & \multirow[t]{2}{*}{ RCT } & \multirow[t]{2}{*}{$\begin{array}{l}\text { From April } 2007 \\
\text { to June } 2008\end{array}$} & \multirow[t]{2}{*}{$\begin{array}{l}1 \text { Primary } \\
\text { care practice }\end{array}$} & \multirow[t]{2}{*}{60} & \multirow[t]{2}{*}{$9(16)$} & \multirow[t]{2}{*}{$0(0)^{*}$} & \multirow[t]{2}{*}{$29 / 29$} & \multirow[t]{2}{*}{$6 w k$} & $\begin{array}{l}\text { Intervention group: } \\
0 / 29(0 \%)\end{array}$ & \multirow[t]{2}{*}{ Not used } \\
\hline & & & & & & & & & & & $\begin{array}{l}\text { Control group: } \\
0 / 29(0 \%)\end{array}$ & \\
\hline \multirow[t]{2}{*}{ Ciechanowski et al. [31] } & \multirow[t]{2}{*}{2006} & \multirow[t]{2}{*}{ US } & \multirow[t]{2}{*}{$\mathrm{RCT}$} & \multirow[t]{2}{*}{ Not clear } & \multirow{2}{*}{$\begin{array}{l}9 \text { health } \\
\text { maintenance } \\
\text { organization } \\
\text { clinics }\end{array}$} & \multirow[t]{2}{*}{58} & \multirow[t]{2}{*}{$112(36)$} & \multirow[t]{2}{*}{$248(78)$} & \multirow[t]{2}{*}{$160 / 164$} & $\begin{array}{l}3,6 \\
12 \mathrm{mo}\end{array}$ & $\begin{array}{l}\text { Intervention group: } \\
0 / 160(0 \%)\end{array}$ & Used \\
\hline & & & & & & & & & & & $\begin{array}{l}\text { Control group: } \\
\text { 0/164 (0\%) }\end{array}$ & \\
\hline Ell et al. [32] & 2011 & US & RCT & $\begin{array}{l}\text { From August } 2005 \\
\text { to August } 2007\end{array}$ & $\begin{array}{l}2 \text { public } \\
\text { safety-net }\end{array}$ & $\begin{array}{l}\text { Not } \\
\text { clear }^{* *}\end{array}$ & $69(18)$ & $\begin{array}{l}\text { Not } \\
\text { clear }^{* * *}\end{array}$ & 193/194 & $\begin{array}{l}6,12,18 \\
24 \mathrm{mo}\end{array}$ & $\begin{array}{l}\text { Intervention group: } \\
55 / 193(28.5 \%)\end{array}$ & Used \\
\hline & & & & & & & & & & & $\begin{array}{l}\text { Control group: } \\
68 / 194(35.1 \%)\end{array}$ & \\
\hline Katon et al. [19] & 2010 & US & RCT & $\begin{array}{l}\text { From May } 2007 \\
\text { to October } 2009\end{array}$ & $\begin{array}{l}14 \text { Primary } \\
\text { care clinics }\end{array}$ & 57 & $103(48)$ & $169(79)$ & $106 / 108$ & $6,12 \mathrm{mo}$ & $\begin{array}{l}\text { Intervention group: } \\
12 / 106(11.3 \%)\end{array}$ & Used \\
\hline & & & & & & & & & & & $\begin{array}{l}\text { Control group: } \\
16 / 108(14.8 \%)\end{array}$ & \\
\hline Katon et al. [23] & 2004 & US & RCT & $\begin{array}{l}\text { From March } 2001 \\
\text { to May } 2002\end{array}$ & $\begin{array}{l}9 \text { Primary } \\
\text { care clinics }\end{array}$ & 58 & $115(35)$ & $260(79)$ & $164 / 165$ & $\begin{array}{l}3,6,9 \\
12 \mathrm{mo}\end{array}$ & $\begin{array}{l}\text { Intervention group: } \\
21 / 164(13 \%)\end{array}$ & Used \\
\hline & & & & & & & & & & & $\begin{array}{l}\text { Control group: } \\
16 / 165 \text { (9.7\%) }\end{array}$ & \\
\hline Kinder et al. [33] & 2006 & US & RCT & Not clear & $\begin{array}{l}\text { Primary care } \\
\text { clinics }\end{array}$ & 58 & $115(35)$ & $248(75)$ & $164 / 165$ & $6,12 \mathrm{mo}$ & $\begin{array}{l}\text { Intervention group: } \\
\text { 18/164 (11.0\%) }\end{array}$ & Not used \\
\hline & & & & & & & & & & & $\begin{array}{l}\text { Control group: } \\
23 / 165 \text { (13.9\%) }\end{array}$ & \\
\hline Williams Jr et al. [28] & 2004 & US & RCT & $\begin{array}{l}\text { From July } 1999 \\
\text { to August } 2001\end{array}$ & $\begin{array}{l}18 \text { Primary } \\
\text { care clinics }\end{array}$ & 70 & $194(47)$ & $265(64)$ & $205 / 212$ & $\begin{array}{l}3,6 \\
12 \mathrm{mo}\end{array}$ & $\begin{array}{l}\text { Intervention group: } \\
5 / 205(2.4 \%)\end{array}$ & Used \\
\hline & & & & & & & & & & & $\begin{array}{l}\text { Control group: } \\
\text { 19/212 (9.0\%) }\end{array}$ & \\
\hline
\end{tabular}

Abbreviations: mo month, SCL-20 Symptom Checklist-20, RCT Randomized Controlled Trial, US United States, wk week.

* $100 \%$ African American.

** $72 \%>=50$ years.

***96\% Hispanic. 
mean differences (MDs) with 95\% CI for continuous variables. Results were considered statistically significant when $P<0.05$. The possibility of publication bias was initially planned to be evaluated by funnel plots, but not adopted eventually either because of the limited number of trials included or the significant heterogeneity among trials [38]. No additional analysis was performed. No protocol of the present review has been published or registered.

\section{Results}

\section{Literature search}

We identified 1,467 citations (Figure 1). After excluding 103 duplicate records, two authors (YH XW) screened 1,364 titles and abstracts to identify the potentially relevant studies. Totally 217 full-text articles were assessed for eligibility. Of these, 10 studies were included in qualitative synthesis $[2,19,23,24,26,27,31-33]$. A total of 8 articles met the final eligibility criteria for meta-analysis $[19,23,26,27,31-33]$. The detailed selection process was described in Figure 1.

\section{Characteristics of the included studies}

Table 1 summarized the basic characteristics of the included randomized controlled trials. There were 8 studies with a total of 2,238 patients with both depression and diabetes, which compared collaborative care with usual care [19,23,26,27,31-33]. All trials were from the United States. One trial included only African Americans [27]. Two trials included only old patients (aged or above 50 and 60 respectively) [27,28]. Three trials used enhanced usual care for the control group [19,31,32] and five trials used normal usual care [23,26-28,33]. Duration of trials varied from 13 months to 30 months.

Random sequence generation [23,28,31,32] and allocation concealment $[19,23,28,32]$ were described adequately in four studies respectively. Blinding of patients was not possible. Therefore, all studies had high risk of bias in blinding. Five studies [19,23,28,36,38,] described adequate blinding of outcome assessment. Two studies $[19,23]$ did not provide sufficient information for assessment of incomplete outcome data. Six studies [19,23,28,31-33] reported all expected outcomes. The detailed risk of bias of all included trials was shown in Table 2.

\section{Depression treatment response and depression remission at the end of follow up}

Four trials provided information on treatment response rate to calculate the overall effect size, with 1,096 patients $[19,23,32,33]$. The length treatment ranged from 12 to 24 month. All of these trials reported an increased treatment response rate in the collaborative group, and one was significant $(\mathrm{RR}=1.96,95 \% \mathrm{CI}=1.38-2.78)$ [19]. Pooling of the mean proportion showed that $44.8 \%$ of patients in intervention group and $34.3 \%$ of patients in control group had treatment responses. The meta-analysis showed that collaborative care was associated with a significant increase in treatment response rate at the end of follow up $(\mathrm{RR}=1.33,95 \% \mathrm{CI}=1.05-1.68 ; P=0.06$ for heterogeneity; $\mathrm{I}^{2}=59 \%$ ) (Figure $2 \mathrm{~A}$ ). The RR of 1.33 indicated a $33 \%$ relative increase in treatment response rate was added to collaborative care. There was significant heterogeneity in the studies.

Two trials reported information on depression remission rate $[32,33]$. Of these, one showed a significant improvement on remission rate in collaborative care group at the end of the 24 month's treatment (adjusted $R R=1.53$, 95\% $\mathrm{CI}=1.11-2.12$ ) [32]. Another reported a non-significant improvement [33]. There were 552 patients to calculate the overall effect size. The meta-analysis indicated that there was a non-significant effect of collaborative care $(\mathrm{RR}=1.15,95 \% \mathrm{CI}=0.87-1.52 ; P=0.33$ for heterogeneity; $\mathrm{I}^{2}=0 \%$ ) (Figure 2B).

\section{Depression treatment response at 6 and 12 months follow up}

Four trials evaluated treatment response rate at 6 months follow up, with totally 1,118 patients [19,23,32,33]. All reported an increased treatment response rate in the collaborative group, and three were significant. Combining the four trials also demonstrated a statistically significantly beneficial effect of collaborative care at 6 months follow up $(\mathrm{RR}=1.64,95 \% \mathrm{CI}=1.28-2.10 ; P=0.09$ for heterogeneity; $\mathrm{I}^{2}=54 \%$ ) (Figure 3A).

Four trials provided information to calculate the overall effect size of treatment response rate at 12 months follow up, with 1,344 patients $[19,23,32,33]$. All of these trials reported an increased treatment response rate in the collaborative group, and two were significant. The meta-analysis showed that collaborative care was associated with a significant increase in treatment response at 12 months follow up $(\mathrm{RR}=1.42,95 \% \mathrm{CI}=1.14-1.76 ; P=0.10$ for heterogeneity; $\mathrm{I}^{2}=52 \%$ ) (Figure 3B).

\section{Depression remission at 6 and 12 months follow up}

Two trials reported depression remission rate at 6 months follow up, with an evaluation of 595 patients to calculate the overall effect size [32,33]. Both of the trials reported an increased treatment response rate in the collaborative group, neither of them was significant. However, the combined results indicated a significant increase with collaborative care $(\mathrm{RR}=1.33,95 \% \mathrm{CI}=1.01-1.75 ; P=0.70$ for heterogeneity; $\mathrm{I}^{2}=0 \%$ ) (Figure $3 \mathrm{C}$ ).

Two trials reported information on depression remission at 12 months follow up, with an evaluation of 569 patients to calculate the overall effect size [32,33]. The meta-analysis resulted in a non-significant effect on depression remission 
Table 2 The risk of bias of included studies

\begin{tabular}{|c|c|c|c|c|c|c|c|c|}
\hline \multirow[t]{2}{*}{ Studies } & \multirow[t]{2}{*}{ Year } & \multicolumn{2}{|c|}{ Selection bias } & \multirow{2}{*}{$\begin{array}{l}\text { Performance bias } \\
\text { Blinding } \\
\text { of participants } \\
\text { and personnel }\end{array}$} & \multirow{2}{*}{$\begin{array}{l}\text { Detection bias } \\
\text { Blinding } \\
\text { of outcome } \\
\text { assessment }\end{array}$} & \multirow{2}{*}{$\begin{array}{l}\text { Attrition bias } \\
\text { Incomplete } \\
\text { outcome } \\
\text { data }\end{array}$} & \multirow{2}{*}{$\begin{array}{l}\text { Reporting bias } \\
\text { Selective } \\
\text { reporting }\end{array}$} & \multirow{2}{*}{$\begin{array}{l}\text { Other bias } \\
\text { Anything } \\
\text { else, ideally } \\
\text { prespecified }\end{array}$} \\
\hline & & $\begin{array}{l}\text { Random } \\
\text { sequence } \\
\text { generation }\end{array}$ & $\begin{array}{c}\text { Allocation } \\
\text { concealment }\end{array}$ & & & & & \\
\hline Bogner et al. [26] & 2012 & U & U & $\mathrm{H}$ & U & $\mathrm{L}$ & U & U \\
\hline Bogner et al. [27] & 2010 & $U$ & $U$ & $\mathrm{H}$ & $U$ & L & $U$ & $U$ \\
\hline Ciechanowski et al. [31] & 2006 & $\mathrm{~L}$ & U & $\mathrm{H}$ & $L$ & $L$ & $L$ & U \\
\hline Ell et al. [32] & 2011 & $\mathrm{~L}$ & $\mathrm{~L}$ & $\mathrm{H}$ & L & $\mathrm{L}$ & L & $U$ \\
\hline Katon et al. [19] & 2010 & U & $\mathrm{L}$ & $\mathrm{H}$ & $L$ & U & $L$ & U \\
\hline Katon et al. [23] & 2004 & L & $\mathrm{L}$ & $\mathrm{H}$ & L & U & L & U \\
\hline Kinder et al. [33] & 2006 & U & U & $\mathrm{H}$ & U & L & $L$ & U \\
\hline Williams Jr et al. [28] & 2004 & $\mathrm{~L}$ & $\mathrm{~L}$ & $\mathrm{H}$ & $L$ & $\mathrm{~L}$ & L & U \\
\hline
\end{tabular}

$H$ high risk of bias, $L$ low risk of bias, $U$ unclear risk of bias.

at 12 months follow up $(\mathrm{RR}=1.20,95 \% \mathrm{CI}=0.93-1.55$; $P=0.48$ for heterogeneity; $\mathrm{I}^{2}=0 \%$ ) (Figure 3D).

Diabetes clinical outcomes (HbA1c values) at the end of follow up

Seven trials reported HbA1c values. One trial [26] showed a significant reduction on HbA1c values in collaborative care group at the end of follow up. Another trial [24] showed that the percentage of patients with HbA1c values less than 7 was $60.9 \%$ and $35.7 \%$ in collaborative care group and usual care group respectively (no statistical analysis provided). The other five trials $[19,23,27,28,32]$ provided information to calculate the overall effect size at the end of follow up, with totally 1,094 patients. Of these, only one was significant $(\mathrm{MD}=-0.48,95 \% \mathrm{CI}=-0.91-0.05)$ [19]. The analysis of the pooled data from the five trials demonstrated a reduction in $\mathrm{HbA} 1 \mathrm{c}$ values at the end of follow up in favor of collaborative care $(\mathrm{MD}=-0.13$, $95 \% \mathrm{CI}=-0.46-0.19 ; P=0.08$ for heterogeneity; $\left.\mathrm{I}^{2}=51 \%\right)$ although this was not statistically significant (Figure 4).

\section{Diabetes clinical outcomes (HbA1c values) at 6 and}

12 months follow up

Four trials evaluated HbA1c values at 6 months follow up, with 1,101 patients to calculate the overall effect size $[19,23,28,32]$. There was a non-significant reduction in

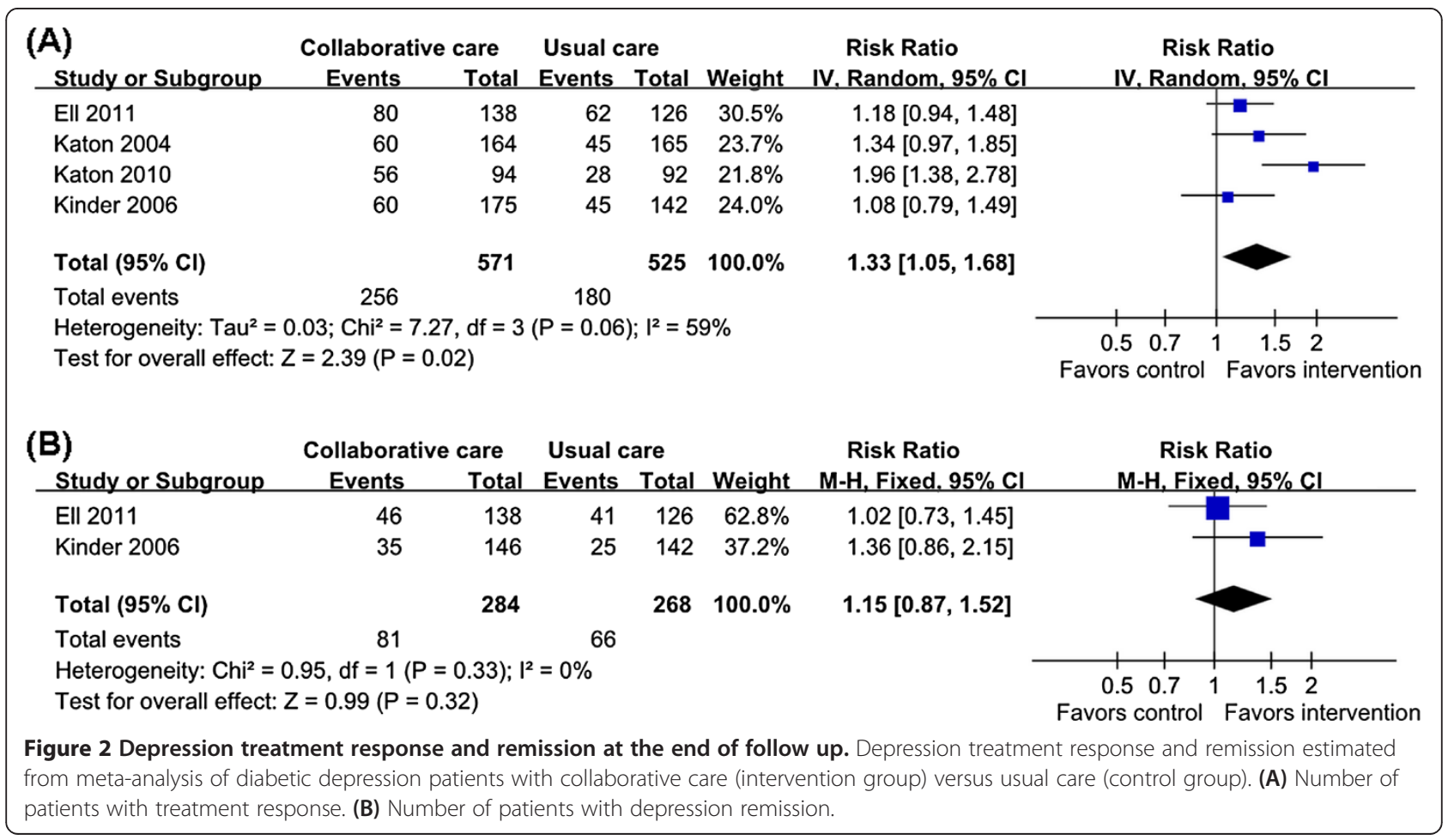




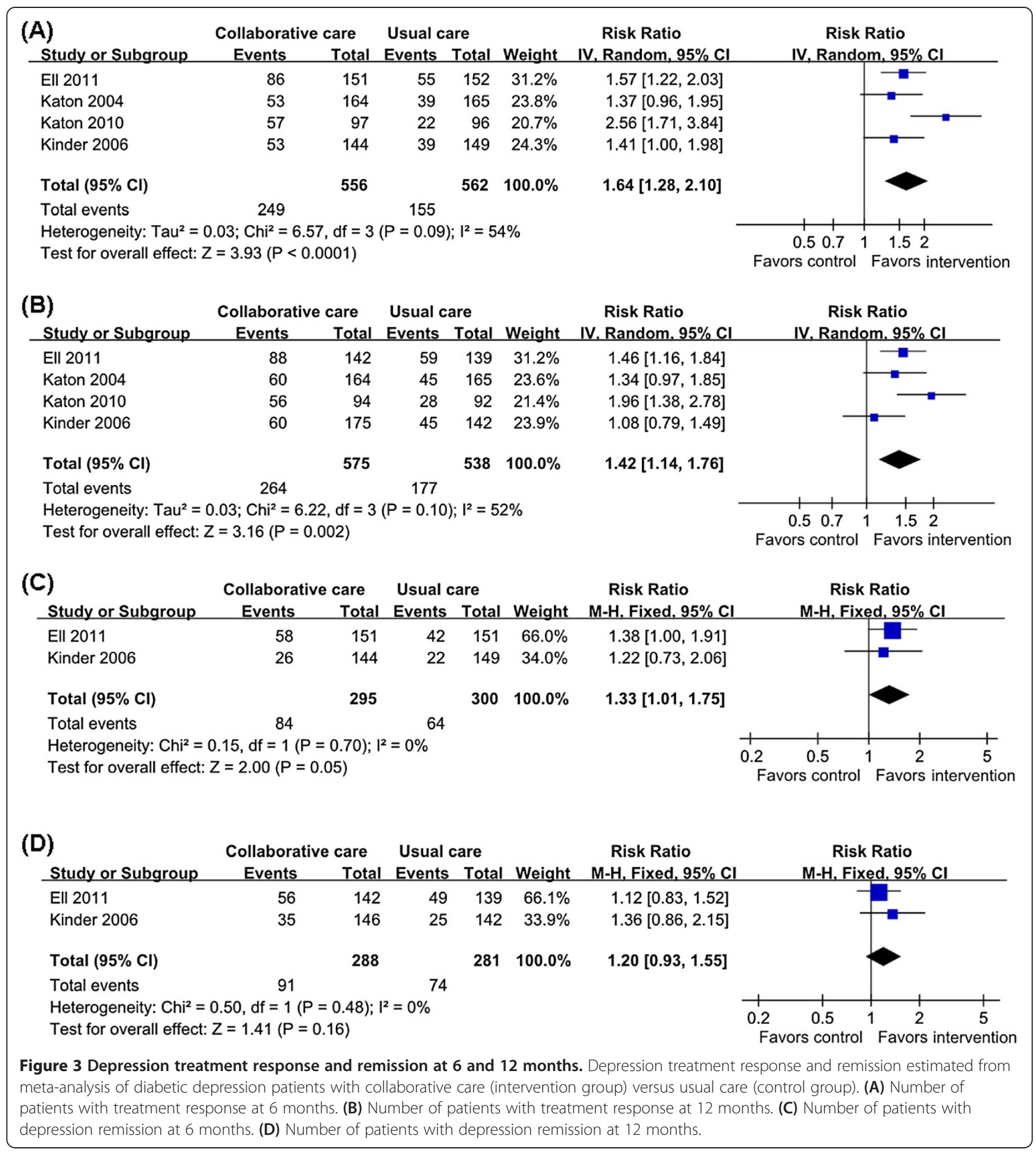

HbA1c values in favor of collaborative care $(\mathrm{MD}=-0.06$, 95\% CI $=-0.24-0.12 ; P=0.31$ for heterogeneity; $\mathrm{I}^{2}=16 \%$ ) (Figure 5A).

Four trials evaluated HbA1c values at 12 months follow up, with 1,053 patients to calculate the overall effect size $[19,23,28,32]$. The analysis of the pooled data from the four trials demonstrated a reduction in $\mathrm{HbA} 1 \mathrm{c}$ values at 12 months follow up in favor of collaborative care
$(\mathrm{MD}=-0.07,95 \% \mathrm{CI}=-0.28-0.13 ; P=0.20$ for heterogeneity; $\mathrm{I}^{2}=36 \%$ ) although this was not statistically significant (Figure 5B).

Adherence to antidepressant medication and oral hypoglycemic agent

Four trials reported rates of adherence to antidepressant medication, all provided information to calculate the 


\begin{tabular}{|c|c|c|c|c|c|c|c|c|c|}
\hline \multirow[b]{2}{*}{ Study or Subgroup } & \multicolumn{3}{|c|}{ Collaborative care } & \multicolumn{3}{|c|}{ Usual care } & \multirow[b]{2}{*}{ Weight } & \multirow{2}{*}{$\begin{array}{l}\text { Mean Difference } \\
\text { IV. Random. } 95 \% \mathrm{Cl}\end{array}$} & \multirow{2}{*}{$\begin{array}{c}\text { Mean Difference } \\
\text { IV, Random, } 95 \% \mathrm{CI}\end{array}$} \\
\hline & Mean & SD & Total & Mean & SD & Total & & & \\
\hline Bogner 2010 & 6.7 & 2.3 & 29 & 7.9 & 2.6 & 29 & $5.7 \%$ & $-1.20[-2.46,0.06]$ & \\
\hline Ell 2011 & 9.1 & 3.41 & 138 & 8.87 & 3.26 & 126 & $11.8 \%$ & $0.23[-0.57,1.03]$ & \\
\hline Katon 2004 & 7.69 & 1.56 & 164 & 7.59 & 1.58 & 165 & $29.4 \%$ & $0.10[-0.24,0.44]$ & \\
\hline Katon 2010 & 7.33 & 1.21 & 105 & 7.81 & 1.9 & 106 & $24.6 \%$ & $-0.48[-0.91,-0.05]$ & \\
\hline Williams Jr 2004 & 7.11 & 1.33 & 122 & 7.11 & 1.42 & 110 & $28.5 \%$ & $0.00[-0.36,0.36]$ & \\
\hline Total $(95 \% \mathrm{Cl})$ & & & 558 & & & 536 & $100.0 \%$ & $-0.13[-0.46,0.19]$ & \\
\hline \multicolumn{8}{|c|}{$\begin{array}{l}\text { Heterogeneity: } \mathrm{Tau}^{2}=0.06 ; \mathrm{Chi}^{2}=8.19, \mathrm{df}=4( \\
\text { Test for overall effect: } \mathrm{Z}=0.79(P=0.43)\end{array}$} & $\mathrm{Fa}$ & $\begin{array}{ccccc}-1 & -0.5 & 0 & 0.5 & 1 \\
\text { Favors intervention } & \text { Favors control }\end{array}$ \\
\hline
\end{tabular}

overall effect size [23,26,27,31]. There were a total of 891 patients. All the four trials reported a significant improvement on adherence to antidepressant medication. The meta-analysis also indicated a statistical significant positive effect on rates of adherence to antidepressant medication $(\mathrm{RR}=1.79,95 \% \mathrm{CI}=1.19-2.69 ; P<0.001$ for heterogeneity; $\mathrm{I}^{2}=84 \%$ ) (Figure 6A).

Two trials provided information to calculate the pooled effect size on adherence to oral hypoglycemic agent, with a total of 238 patients $[26,27]$. Both of them showed a significant improvement on adherence to oral hypoglycemic agent. The pooled data indicated that collaborative care was associated with a significant improvement of adherence to oral hypoglycemic agent $(\mathrm{RR}=2.18,95 \% \mathrm{CI}=1.61-2.96$; $\mathrm{P}=0.60$ for heterogeneity; $\mathrm{I} 2=0 \%$ ) (Figure $6 \mathrm{~B})$.

\section{Discussion}

The present study comprehensively summarized current evidences from 8 RCTs to examine if collaborative care can work as a truly integrated intervention to improve both depression and diabetes outcomes, comparing with usual care. We found that collaborative care significantly improved depression outcomes, as well as adherence to antidepressant medication and oral hypoglycemic agent. Though there were significant heterogeneity in the meta-analyses, we found results from large RCTs were consistent $[19,31,32]$, which strengthened the robustness of our conclusion.

Our study showed that collaborative care improved depression treatment response of diabetic patients with depression. All combined results showed positive effects

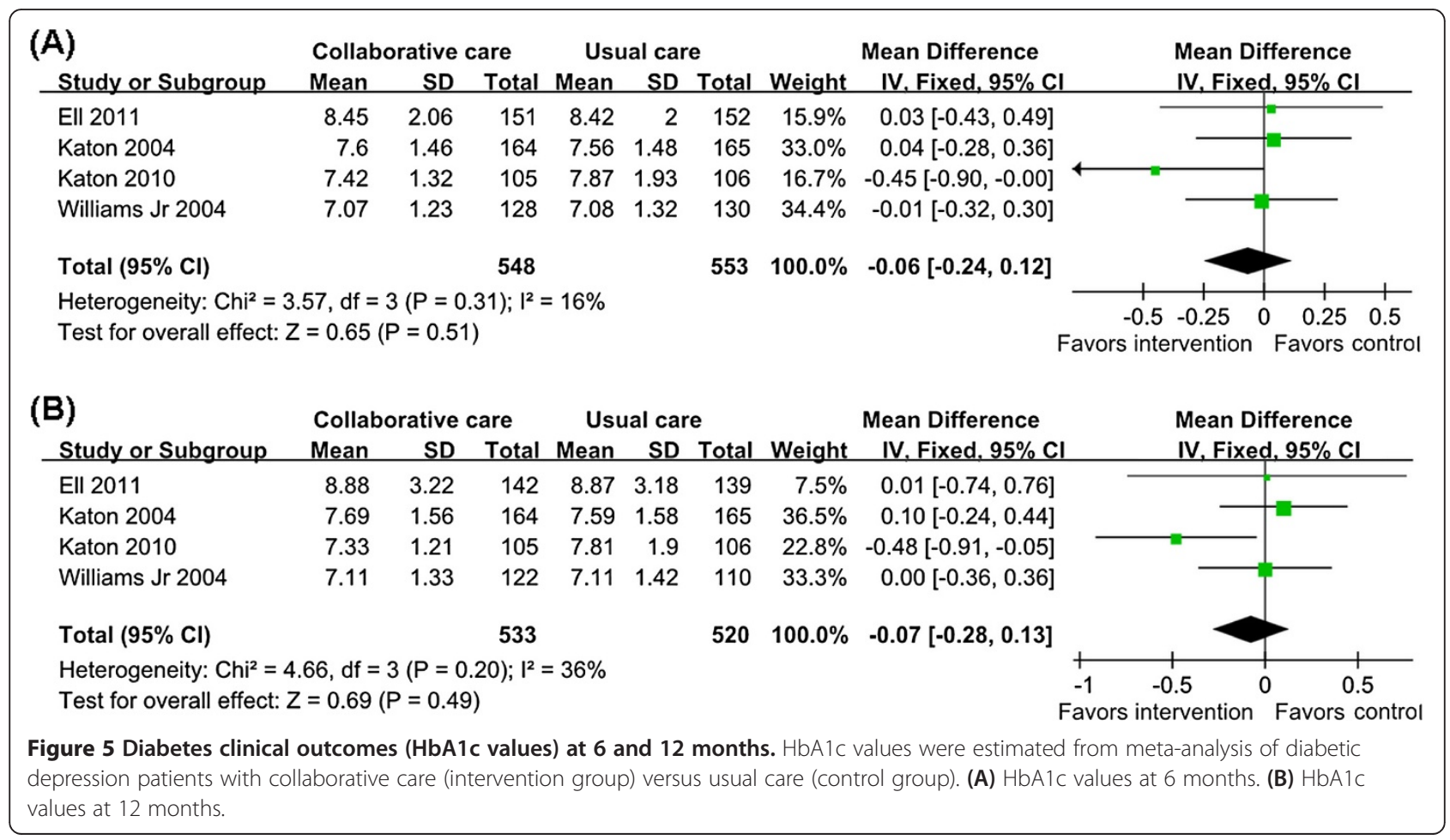




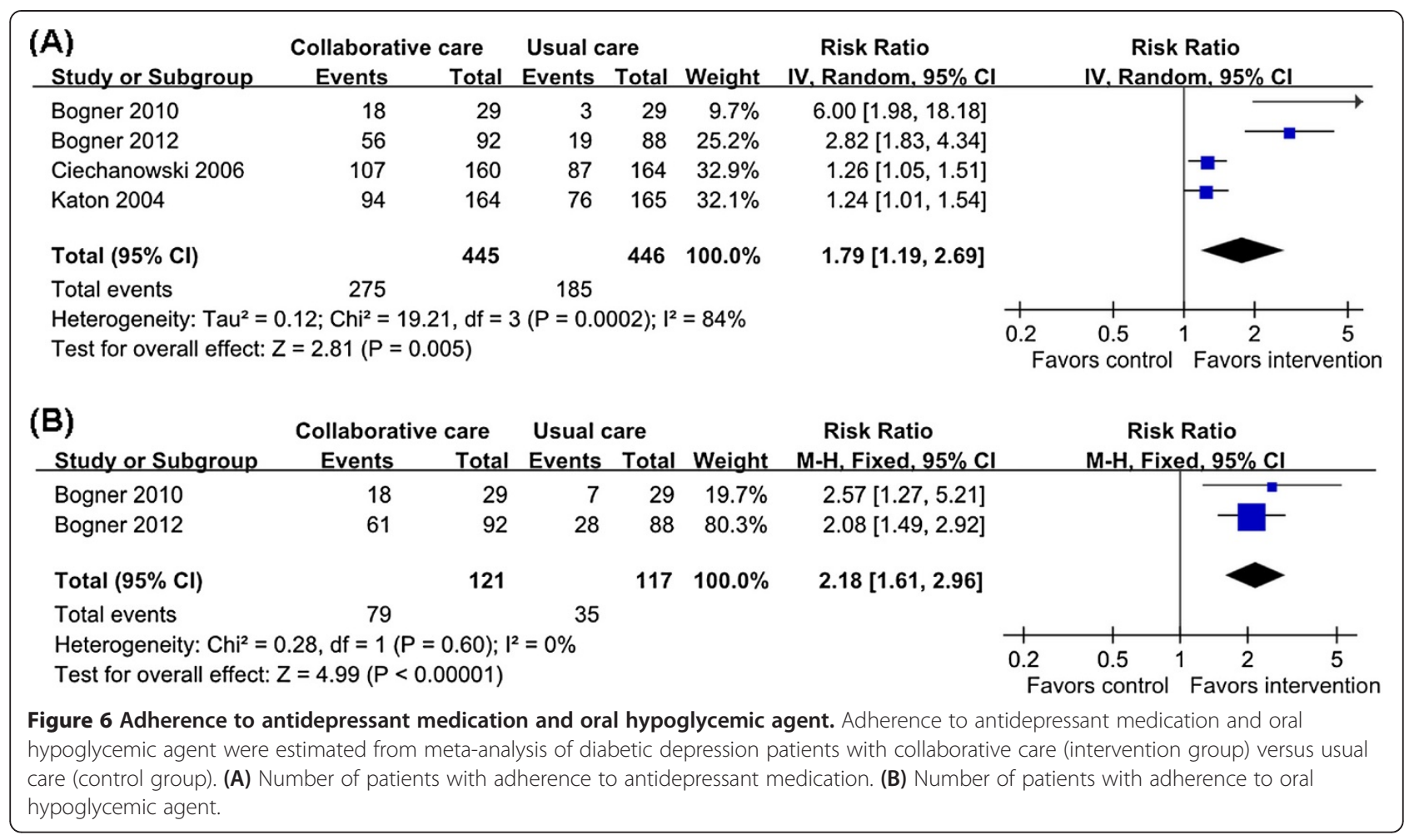

on depression treatment response at 6 months, 12 months and the end of follow up. Moreover, the improvement in the outcome at the end of follow up compared favorably with response rates in collaborative care trials, which included patients with and without long term conditions. For example, a previous meta-analysis of 79 RCTs of collaborative care for depression showed a RR of $1.29(95 \% \mathrm{CI}=1.18-1.41)$ [12] versus a $\mathrm{RR}$ of 1.33 (95\% CI $=1.05-1.68)$ in our study.

Collaborative care model was also significantly associated with higher rates of both adherence to antidepressant medication $(\mathrm{RR}=1.79,95 \% \mathrm{CI}=1.19-2.69)$ and oral hypoglycemic agent $(R R=2.18,95 \% C I=1.61-2.96)$ in depressed patients with diabetes. These results are encouraging. Previous studies showed that depression was significantly associated with poor adherence to medication in diabetic patients $[8,15,39]$. In view of the challenges that faced by physicians in primary care practices, collaborative care are most likely helpful to improving adherence rate of medication among depressed patients with diabetes.

The effects of collaborative care on depression remission rates were limited at the end of follow up. According to our combined results, it seems that collaborative care did not benefit long term depression remission $(R R=1.15,95 \%$ $\mathrm{CI}=0.87-1.52$ ). This data was mainly based on the crude RRs or crude odds ratios (ORs) that reported in original RCTs. Most of the authors of these original RCTs only reported the crude RRs or ORs without adjusting the potential confounders (for example, age, base line SCL-20 and HbA1c values). In study of Ell et al [32], the authors anticipated these confounders and provided the adjusted analysis for collaborative care versus usual care, which showed a signification increase in depression remission at the end of follow up (adjusted RR $=1.53,95 \%$ $\mathrm{CI}=1.11-2.12)$. However, the data could not be combined since there was only one study reported the adjusted results of this outcome. In the future, the trialists are recommended to report both adjusted and unadjusted results to prevent the potential selection bias [40,41]. In addition, our meta-analysis showed that collaborative care also improved treatment remission rates at 6 months follow up, but this effect was modest.

Out meta-analyses showed that the improvements of outcomes of depression were not accompanied by significant differences in HbA1c values between patients in collaborative care and usual care group. HbA1c values were not affected at 6 months, 12 months and the end of follow up. Of the trials included in qualitative synthesis, three of them $[19,26,27]$ had found that collaborative care was associated with improved HbA1c values, and two of them was significant $[19,26]$. Given that diabetic patients with depression usually have more macrovascular and microvascular complications and higher numbers of risk factors than diabetic patients without depression, the collaborative care that focuses on improving management of both depression and diabetes are likely to be needed in the future, to improve clinical outcomes at a population level in both of chronic illnesses [19]. 


\section{Limitations of the review}

Combining the results from different trials generated significant variations in outcomes. In meta-analyses of primary outcomes, there existed a significant heterogeneity in the overall results of depression treatment response. The values of $\mathrm{I}^{2}$ are 54\%, 52\% and 59\% for treatment response at 6 months, 12 months and the end of follow up respectively, which were all represented moderate levels of heterogeneity [42]. We therefore used random effects models to combine the data of these outcomes. Collaborative care is a kind of complex intervention with a considerable variability involving separate mechanisms, which is difficult to specify and define [29]. Nevertheless, compared with previous reviews [22,43], which using broader inclusion criteria for collaborative care, this review was based on more precise definition of collaborative care $[12,30]$.

We were unable to collect addition information from authors who were responded for the original studies. There might be some missing data. In addition, using the Cochrane Collaboration's tool for assessing risk of bias, we have identified methodological limitations in the studies. For example, all studies were rated as high risk of bias for blinding of participants and personnel.

Last but not least, this meta-analysis was based on 8 RCTs with 2,238 patients from different primary care practices in the United States, which might not be representative of all patients with both diabetes and depression around the world. Further research is needed to help clarify whether collaborative care can be implemented outside the United States.

\section{Conclusions}

In summary, collaborative care model significantly improves depression outcomes and adherence to medication in diabetic patients with depression, comparing with usual care. Collaborative care is recommended for patients with both depression and diabetes in the future.

\section{Additional files}

Additional file 1: Search strategies.

Additional file 2: Additional information of the included studies.

\section{Competing interests}

The authors declare that they have no competing interests.

\section{Authors' contributions}

$A G$ and $Y H$ conceived and designed the experiments. $Y H, A G, X W$, TW and $\mathrm{RC}$ involved in the interpretation of the results. $\mathrm{YH}$ and $\mathrm{AG}$ performed the experiments. $Y H, X W, T W$ and $R C$ analyzed the data. $Y H$ and $A G$ wrote the paper. All authors read and approved the final manuscript.

\section{Acknowledgments}

We are grateful for the support of National Training Center for General Practice Ministry of Health China.

\section{Author details}

${ }^{1}$ School of General Practice and Continuing Education, Capital Medical University, Beijing 100069, China. ²Datun Community Health Service Center, Beijing Anzhen Hospital, Capital Medical University, Beijing 100029, China. ${ }^{3}$ Research Department, Beijing Anzhen Hospital, Capital Medical University, Beijing 100029, China.

Received: 23 May 2013 Accepted: 1 October 2013

Published: 14 October 2013

\section{References}

1. Bogner HR, Morales KH, Post EP, Bruce ML: Diabetes, depression, and death: a randomized controlled trial of a depression treatment program for older adults based in primary care (PROSPECT). Diabetes Care 2007, 30:3005-3010.

2. Lin EHB, Katon W, Rutter C, Simon GE, Ludman EJ, Von Korff M, Young B, Oliver M, Ciechanowski PC, Kinder L, Walker E: Effects of enhanced depression treatment on diabetes self-care. Ann Fam Med 2006, 4:46-53.

3. Gask L, Ludman E, Schaefer J: Qualitative study of an intervention for depression among patients with diabetes: how can we optimize patientprofessional interaction? Chronic IIIn 2006, 2:231-242.

4. Ali S, Stone MA, Peters JL, Davies MJ, Khunti K: The prevalence of co-morbid depression in adults with Type 2 diabetes: a systematic review and meta-analysis. Diabet Med 2006, 23:1165-1173.

5. Anderson RJ, Freedland KE, Clouse RE, Lustman PJ: The prevalence of comorbid depression in adults with diabetes: a meta-analysis. Diabetes Care 2001, 24:1069-1078.

6. Rotella F, Mannucci E: Depression as a risk factor for diabetes: a metaanalysis of longitudinal studies. J Clin Psychiatry 2013, 74:31-37.

7. Bogner HR, de Vries HF, O'Donnell AJ, Morales KH: Measuring concurrent oral hypoglycemic and antidepressant adherence and clinical outcomes. Am J Manag Care 2013, 19:e85-e92.

8. Gonzalez JS, Peyrot M, McCarl LA, Collins EM, Serpa L, Mimiaga MJ, Safren SA: Depression and diabetes treatment nonadherence: a meta-analysis. Diabetes Care 2008, 31:2398-2403.

9. DiMatteo MR, Lepper HS, Croghan TW: Depression is a risk factor for noncompliance with medical treatment: meta-analysis of the effects of anxiety and depression on patient adherence. Arch Intern Med 2000, 160:2101-2107.

10. Mezuk B, Eaton WW, Albrecht S, Golden SH: Depression and type 2 diabetes over the lifespan: a meta-analysis. Diabetes Care 2008, 31:2383-2390.

11. Carnethon MR, Kinder LS, Fair JM, Stafford RS, Fortmann SP: Symptoms of depression as a risk factor for incident diabetes: findings from the National Health and Nutrition Examination Epidemiologic Follow-up Study, 1971-1992. Am J Epidemiol 2003, 158:416-423.

12. Archer J, Bower P, Gilbody S, Lovell K, Richards D, Gask L, Dickens C, Coventry P: Collaborative care for depression and anxiety problems. Cochrane Database Syst Rev 2012, 10, CD006525.

13. Coventry PA, Hays R, Dickens C, Bundy C, Garrett C, Cherrington A, ChewGraham C: Talking about depression: a qualitative study of barriers to managing depression in people with long term conditions in primary care. BMC Fam Pract 2011, 12:10

14. Katon W, Russo J, Frank E, Barrett J, Williams JW Jr, Oxman T, Sullivan M, Cornell J: Predictors of nonresponse to treatment in primary care patients with dysthymia. Gen Hosp Psychiatry 2002, 24:20-27.

15. Lustman PJ, Clouse RE: Depression in diabetic patients: the relationship between mood and glycemic control. J Diabetes Complications 2005, 19:113-122.

16. Rotella F, Mannucci E: Diabetes mellitus as a risk factor for depression. A meta-analysis of longitudinal studies. Diabetes Res Clin Pract 2013, 99:98-104.

17. Kan C, Silva N, Golden SH, Rajala U, Timonen M, Stahl D, Ismail K: A systematic review and meta-analysis of the association between depression and insulin resistance. Diabetes Care 2013, 36:480-489.

18. Harkness E, Macdonald W, Valderas J, Coventry P, Gask L, Bower P: Identifying psychosocial interventions that improve both physical and mental health in patients with diabetes: a systematic review and meta-analysis. Diabetes Care 2010, 33:926-930.

19. Katon WJ, Lin EHB, Korff MV, Ciechanowski P, Ludman EJ, Young B, Peterson D, Rutter CM, McGregor M, McCulloch D: Collaborative care for patients with depression and chronic illnesses. N Engl J Med 2010, 363:2611-2620. 
20. Ell K, Aranda MP, Xie B, Lee PJ, Chou CP: Collaborative depression treatment in older and younger adults with physical illness: Pooled comparative analysis of three randomized clinical trials. Am J Geriatr Psychiatry 2010, 18:520-530.

21. Coventry PA, Lovell K, Dickens C, Bower P, Chew-Graham C, Cherrington A, Garrett C, Gibbons CJ, Baguley C, Roughley K, Adeyemi I, Keyworth C, Waheed W, Hann M, Davies L, Jeeva F, Roberts C, Knowles S, Gask L: Collaborative interventions for circulation and depression (COINCIDE): study protocol for a cluster randomized controlled trial of collaborative care for depression in people with diabetes and/or coronary heart disease. Trials 2012, 13:139.

22. Thota AB, Sipe TA, Byard GJ, Zometa CS, Hahn RA, McKnight-Eily LR, Chapman DP, Abraido-Lanza AF, Pearson JL, Anderson CW, Gelenberg AJ, Hennessy KD, Duffy FF, Vernon-Smiley ME, Nease DE Jr, Williams SP, Community Preventive Services Task Force: Collaborative care to improve the management of depressive disorders: a community guide systematic review and meta-analysis. Am J Prev Med 2012, 42:525-538.

23. Katon WJ, Von Korff M, Lin EH, Simon G, Ludman E, Russo J, Ciechanowski $P$, Walker $E$, Bush $T$ : The pathways study: a randomized trial of collaborative care in patients with diabetes and depression. Arch Gen Psychiatry 2004, 61:1042-1049.

24. Bogner $\mathrm{H}$ : Integrating depression services into DM management. Current Controlled Trials. 2012. http://clinicaltrials.gov/show/NCT01098253.

25. McGregor M, Lin EHB, Katon WJ: TEAMcare: An integrated multicondition collaborative care program for chronic illnesses and depression. J Ambul Care Manage 2011, 34:152-162.

26. Bogner HR, Morales KH, de Vries HF, Cappola AR: Integrated management of type 2 diabetes mellitus and depression treatment to improve medication adherence: a randomized controlled trial. Ann Fam Med 2012, 10:15-22.

27. Bogner HR, de Vries HF: Integrating type 2 diabetes mellitus and depression treatment among African Americans: A randomized controlled pilot trial. Diabetes Educ 2010, 36:284-292.

28. Williams JW Jr, Katon W, Lin EH, Nöel PH, Worchel J, Cornell J, Harpole L, Fultz BA, Hunkeler E, Mika VS, Unützer J: The effectiveness of depression care management on diabetes-related outcomes in older patients. Ann Intern Med 2004, 140:1015-1024.

29. Campbell M, Fitzpatrick $R$, Haines A, Kinmonth AL, Sandercock $P$, Spiegelhalter D, Tyrer P: Framework for design and evaluation of complex interventions to improve health. BMJ 2000, 321:694-696.

30. Gunn J, Diggens J, Hegarty K, Blashki G: A systematic review of complex system interventions designed to increase recovery from depression in primary care. BMC Health Serv Res 2006, 6:88.

31. Ciechanowski PS, Russo JE, Katon WJ, Korff MV, Simon GE, Lin EH, Ludman EJ, Young BA: The association of patient relationship style and outcomes in collaborative care treatment for depression in patients with diabetes. Med Care 2006, 44:283-291.

32. Ell K, Katon W, Xie B, Lee PJ, Kapetanovic S, Guterman J, Chou CP: One-year postcollaborative depression care trial outcomes among predominantly Hispanic diabetes safety net patients. Gen Hosp Psychiatry 2011, 33:436-442

33. Kinder LS, Katon WJ, Ludman E, Russo J, Simon G, Lin EH, Ciechanowski P, Von Korff M, Young B: Improving depression care in patients with diabetes and multiple complications. J Gen Intern Med 2006, 21:1036-1041.

34. Higgins JP, Altman DG, Gøtzsche PC, Jüni P, Moher D, Oxman AD, Savovic J, Schulz KF, Weeks L, Sterne JA: The Cochrane Collaboration's tool for assessing risk of bias in randomised trials. BMJ 2011, 343:d5928.

35. Farmer KC: Methods for measuring and monitoring medication regimen adherence in clinical trials and clinical practice. Clin Ther 1999 21:1074-1090. discussion 1073.

36. Higgins JP, Thompson SG, Deeks JJ, Altman DG: Measuring inconsistency in meta-analyses. BMJ 2003, 327:557-560.

37. Sutton AJ, Abrams KR, Jones DR, Sheldon TA, Song F: Systematic reviews of trials and other studies. Health Technol Assess 1998, 2:1-276.

38. Lau J, loannidis JP, Terrin N, Schmid CH, Olkin I: The case of the misleading funnel plot. BMJ 2006, 333:597-600.

39. Koopmans B, Pouwer F, de Bie RA, van Rooij ES, Leusink GL, Pop VJ: Depressive symptoms are associated with physical inactivity in patients with type 2 diabetes. The DIAZOB Primary Care Diabetes study. Fam Pract 2009, 26:171-173.
40. Yu LM, Chan AW, Hopewell S, Deeks JJ, Altman DG: Reporting on covariate adjustment in randomized controlled trials before and after revision of the 2001 CONSORT statement: a literature review. Trials 2010, 11:59.

41. Attia A: Bias in RCTs: confounders, selection bias and allocation concealment. Middle East Fertil Soc J 2005, 10:258-261.

42. Higgins JPT, Green S: Cochrane Handbook for Systematic Reviews of Interventions. 5.1.0. The Cochrane Collaboration; 2011. http://handbook.cochrane.org.

43. Gilbody S, Bower P, Fletcher J, Richards D, Sutton AJ: Collaborative care for depression: a cumulative meta-analysis and review of longer-term outcomes. Arch Intern Med 2006, 166:2314-2321.

doi:10.1186/1471-244X-13-260

Cite this article as: Huang et al:: Collaborative care for patients with depression and diabetes mellitus: a systematic review and metaanalysis. BMC Psychiatry 2013 13:260.

\section{Submit your next manuscript to BioMed Central and take full advantage of:}

- Convenient online submission

- Thorough peer review

- No space constraints or color figure charges

- Immediate publication on acceptance

- Inclusion in PubMed, CAS, Scopus and Google Scholar

- Research which is freely available for redistribution 